\title{
Cicatrização de feridas contaminadas tratadas com papaína*
}

\section{Healing in contaminated wounds treated with papain}

\author{
Lacy Cardos de Brito Junior ${ }^{1}$, Pollyanna de Lucena Ferreira ${ }^{2}$
}

\begin{abstract}
RESUMO
Introdução: A papaína, uma enzima de origem vegetal, há muito é utilizada como alternativa para o tratamento de feridas associadas a processos infecciosos exuberantes, devido aos seus efeitos antiinflamatórios e cicatrizantes. Objetivos: Estudar os aspectos histológicos da cicatrização de feridas contaminadas tratadas com papaína. Métodos: Foram utilizados ratos Wistar $(n=18)$, machos, adultos, que passaram por procedimento cirúrgico para a retirada de uma seção quadrada de pele da região cervical dos mesmos, e que foram divididos em dois grupos: Grupo I - Controle $(n=9)$, contaminados com $S$. aureus e sem tratamento; e Grupo II - Tratado $(n=9)$, contaminados com $S$. aureus e tratados com soluções de papaína de 10\%,6\% e 4\%, de acordo com as características das lesões. A análise histológica das áreas lesadas, coradas com Hematoxilina-eosina, foi realizada com 7, 14 e 21 dias. Resultados: Verificamos que a papaína auxiliou na modulação do processo inflamatório; formação e amadurecimento do tecido de granulação; organização das fibras colágenas; e aceleração da proliferação e organização da epiderme em feridas contaminadas, em todos os dias estudados. Conclusões: Nossos dados reforçam e complementam pesquisas que relacionam os efeitos cicatrizantes da papaína sobre feridas contaminadas.
\end{abstract}

Palavras-Chaves: Cicatrização de Feridas; Papaína; Úlcera; Staphylococcus aureus.

\begin{abstract}
Introduction: Papain, an enzyme of vegetal origin, is widely used for the treatment of wounds, especially because of its anti-inflammatory and healing properties. Objectives: Study the histology of healing of wounds treated with papaine solutions Methods: A square section of skin was surgically removed from the cervical region of adult-male Wistar rats $(n=18)$, which were divided into two groups: Group I - Control $(n=9)$, contaminated with $S$. aureus and untreated; and Group II - Treated $(n=9)$ contaminated with $S$. aureus and treated with 10,6 and 4\% papain solutions, according to the macroscopic morphological characteristics of the lesions. A histological analysis was made of the lesions, stained with hematoxilin and eosin and with Masson's trichrome, at 7, 14 and 21 days. Results: The papain aided in the modulation of the inflammatory process, in the formation and maturation of the granulation tissue, and in the organization of the collagenous fibers; accelerating the proliferation and organization of the epidermis at the wounds throughout the healing process. Conclusions: Our data reinforce and complement previous research that details the healing effects of papain on contaminated wounds.
\end{abstract}

Keywords: Wound Healing; Papain; Ulcer; Staphylococcus aureus.

1. Professor Doutor Adjunto IV do Instituto de Ciências Biológicas da UFPA. Responsável Técnico pelo Laboratório de Patologia Geral - Imunopatologia e Citologia da UFPA.

2. Biomédica pela Universidade Federal do Pará

* Trabalho realizado no Laboratório de Patologia Geral -Imunopatologia e Citologia do Centro de Ciências Biológicas da UFPA

Conflito de interesses: nenhum.
Correspondência:

Prof. Dr. Lacy Cardoso de Brito Junior / Icdbrito@ufpa.br Universidade Federal do Pará Instituto de Ciências Biológicas Laboratório de Patologia Geral - Imunopatologia e Citologia Av. Augusto Corrêa n 01, Bairro Guamá CEP 66075-900 - Belém - Pará

Artigo recebido em 18/03/2014 Aprovado para publicação em 27/08/2014 


\section{Introdução}

A papaína é uma enzima proteolítica complexa de origem vegetal extraída do látex do mamão (carica papaya), que vem sendo utilizada nas últimas décadas por vários pesquisadores em estudos, tanto a partir da forma bruta como liofilizada, para o auxilio dos processos de cicatrização tecidual, em função do seu poder acelerador de crescimento tecidual, bactericida, bacteriostático e debridante de tecidos necrosados, desvitalizados e infectados. ${ }^{1-25}$

Os poderes de debridamento químico, bactericida e bacteriostático, induzidos pela papaína têm sido exatamente alguns dos fatores responsáveis para que profissionais de saúde no Brasil optem pela utilização desta enzima como recurso curativo em todas as fases do processo de cicatrização de feridas de diversas patologias crônicas, como o "pé diabético", a insuficiência circulatória venosa ou arterial, as úlceras de decúbito e até em algumas patologias viscerais. ${ }^{2,3,9,11,23}$ Outros fatores como seu baixo custo, pouco, ou nenhum, efeito colateral, facilidade de aplicação e sua ação similar à de debridantes químicos autolíticos, porém, com maior seletividade e eficácia na lise específica dos tecidos mortos também falam em favor do seu uso. ${ }^{6,9-12,21,23}$

A indicação da utilização de soluções de papaína, em várias concentrações, durante todas as fases do processo de cicatrização de feridas, entretanto, é dependente das características de cada fase em que se encontra a lesão. Assim, em casos de feridas secas ou com tecido de granulação a indicação na literatura é de que as concentrações de papaína devem variar de $2 \%$ e $4 \%$; quando da presença de exsudato purulento e/ou infecções, estas concentrações devem variar de $4 \%$ a $6 \%$; e quando da presença de tecido necrótico abundante recomenda-se a utilização de papaína na concentração de $10 \%$. $^{10,13,14,23,24}$

A presença, entretanto, de exsudato inflamatório infeccioso, associado a agentes bacterianos como Enterococcus faecalis, Pseudomonas aeruginosa, Staphylococcus aureus, Klebsiella pneumoniae e Escherichia coli, oriundos da flora bacteriana normal do hospedeiro humano, e do ambiente hospitalar são, por sua vez, alguns dos principais interferentes do processo de cicatrização tecidual ${ }^{14,15,16,17,22}$.

O objetivo deste trabalho, então, foi estudar os aspectos histológicos da cicatrização tecidual de feridas sépticas experimentais, contaminadas com Staphylococcus aureus, após o tratamento com soluções de papaína.

\section{Material e Métodos}

\section{Animais de experimentação}

Foram utilizados 18 ratos (Wistar), machos, com pesos entre 200 a 250g; oriundos do Biotério do Instituto de Ciências Biológicas (ICB), distribuídos ao acaso em gaiolas individuais com livre acesso à água e dieta padrão, conforme a descrição dos seguintes grupos experimentais, após aprovação no comitê de ética animal (Parecer $n^{\circ}$ 132.291) deste ICB: Grupo I (Controle), formado por animais que passaram por procedimento cirúrgico, contaminação da lesão com $S$. aureus e que não receberam nenhum tipo de tratamento ( $\mathrm{n}=9)$; e Grupo II (Tratado), formado por animais que passaram também por procedimento cirúrgico, contaminação da lesão com $S$. aureus e que receberam tratamento com soluções de concentrações variadas de papaína $(n=9)$.

\section{Bactérias}

Foram utilizadas bactérias viáveis de Staphylococcus aureus, isoladas a partir de material biológico de pacientes atendidos em um Laboratório de Patologia Clínica, identificadas (bionumeradas) através de método automático VITEK 60 no Setor de Bacteriologia do referido laboratório, cultivo em meio Agar Cled por 24 horas a $37{ }^{\circ} \mathrm{C}$, e posterior repique das colônias para tubos contendo $4 \mathrm{ml}$ de caldo Casoy estéril; para separação dos grumos por agitação mecânica, e ressuspensão em $2 \mathrm{ml}$ de caldo Casoy estéril na concentração de $1,5 \times 10^{8}$ células $/ \mathrm{ml}$. Com esta concentração determinada por método colorimétrico em leitor VITEK colorimeter (product $\mathrm{n}^{\circ}$ 52-1210).

Para a determinação da viabilidade das colônias nas soluções ajustadas $\left(1,5 \times 10^{8}\right.$ células $\left./ \mathrm{ml}\right)$ utilizou-se a retirada de um volume de $0,001 \mathrm{ml}$ com alça de platina calibrada, repique em três placas de Petri contendo meio Ágar Cled e incubação destas em estufa a $37^{\circ} \mathrm{c}$ por 24 horas. Sendo o teste de viabilidade positivo quando se obtinha $83 \%$ de crescimento de Unidades Formadoras de Colônias (UFC).

\section{Procedimento Cirúrgico}

Todos os animais foram anestesiados com 100 $\mathrm{ml}$ quetamine $\mathrm{Kg}$ /peso (i.p.), imobilizados em decúbito ventral, realizada a tricotomia da região dorsal (1,5 cm abaixo do pavilhão auricular na região cervical), assepsia da mesma com álcool a $70 \%$ e posterior procedimento cirúrgico com bisturi, para a retirada 
de uma seção quadrada de pele de aproximadamente $1,5 \mathrm{~cm}$ X $1,5 \mathrm{~cm}$ no sentido crânio-caudal.

Em seguida a exposição da fáscia muscular procedeu-se a contaminação destas áreas cirúrgicas com um volume de $1 \mathrm{ml}$ por animal de solução bacteriana de $S$. aureus ajustada para $1,5 \times 10^{8}$ células $/ \mathrm{ml}$, por meio do gotejamento desta solução sobre a área lesada, de cada animal, com o auxílio de uma seringa estéril de $5 \mathrm{ml}$.

Cessados os efeitos da anestesia os animais foram colocados em gaiolas individuais, com alimentação e água ad libidum.

\section{Preparação da solução de Papaína}

Foi utilizada papaína liofilizada 6.000UI/MG, certificada, proveniente da Índia (Lote de fabricação EXC280212); diluída em tubos do tipo Falcon estéreis contendo $50 \mathrm{ml}$ de água destilada deionizada para obtenção de soluções nas concentrações de 4\% (2g/ $50 \mathrm{ml}), 6 \%(3 \mathrm{~g} / 50 \mathrm{ml})$ e $10 \%(5 \mathrm{~g} / 50 \mathrm{ml})$.

\section{Tratamento das Lesões}

Todos os animais do Grupo II foram tratados, uma vez ao dia, com soluções de papaína a $10 \%$ (nos 7 primeiros dias), $6 \%$ (do $8^{\mathrm{a}}$ dia ao $14^{\circ}$ dia) e $4 \%$ (do $15^{\circ}$ até o $21^{\circ}$ dia), sem a necessidade de cobertura de gazes, e de acordo com as características ( presença de tecido necrosado, crosta hemato-fibrinosa, processo inflamatório, tecido de granulação ou reepitelização) de cada período evolutivo das lesões.

\section{Sacrifícios dos animais}

Todos os animais dos Grupos I (não-tratados) e Grupo II (tratados) foram sacrificados, através de anestesia com $350 \mathrm{ml}$ quetamine $\mathrm{Kg} /$ peso (i.p.) e posterior deslocamento cervical, com 07, 14, e 21 dias, para posterior avaliação histológica dos processos de cicatrização tecidual de acordo com o tratamento adotado.

\section{Estudo histológico}

Todas as áreas das lesões foram retiradas, realizada a fixação do material em formol tamponado a $10 \%$ por 6 horas, seguido de desidratação do material em álcool a $70 \%$, e posterior processamento histológico padrão do material, para confecção de cortes histológicos de $5 \mathrm{~m}$ de espessura e coloração deste material com Hematoxilina-eosina (H\&E) e tricrômico de Masson. A avaliação histológica foi re- alizada em microscopia de luz comum, a partir de estudo "duplo cego" de todos os fragmentos dos 18 animais estudados.

\section{Estudo histométrico}

Todas as lesões, coradas com Hematoxilinaeosina (H\&E) e tricrômico de Masson, foram analisadas quanto a quantidade de leucócitos e fibroblastos em microscopia de luz comum com a utilização de ocular reticulada de 25 pontos acoplada a objetiva com aumento de 100 vezes.

\section{Análise Estatística}

A análise estatística dos dados histométricos foi realizada através análise descritiva e de variância através do ANOVA para dois parâmetros com poshoc Bonforroni utilizando-se o programa BioEstat 5.0, com o nível de significância sendo de $5 \%(\mathrm{P}<0.05)$.

\section{Resultados}

Neste estudo foi observado, macroscopicamente, que as lesões teciduais experimentais contaminadas, induzidas por procedimento cirúrgico e infectadas com $S$. aureus, nos Grupos I (controle não tratado) e Grupo II (tratados com papaína), obedeceram à mesma sequiência de eventos de cicatrização dependentes do tempo como: formação e aumento da espessura da crosta hematofibrinosa, presença de secreção purulenta, aproximação das bordas da lesão e descolamento da crosta hemato-fibrinosa; além de reepitelização da área lesada.

Microscopicamente, entretanto, observou-se que nos animais do Grupo II, tratados com papaína a $10 \%$ por 07 dias, as lesões caracterizaram-se pela presença de moderado exsudato inflamatório mononuclear e necrose tecidual, próximo à borda da lesão; tecido de granulação frouxo, composto por moderadas quantidades de fibroblastos e fibras colágenas; e poucos vasos neoformados (Figuras 1B). Enquanto que nos animais do Grupo I (controle não tratados), para o mesmo período, observou-se a presença de abundante exsudato inflamatório mononuclear e necrose tecidual próximo às bordas da lesão; e tecido de granulação abundante e desorganizado, composto por grandes quantidades de fibroblastos, fibras colágenas e vasos neoformados (Figuras $1^{\mathrm{a}}$ ). 

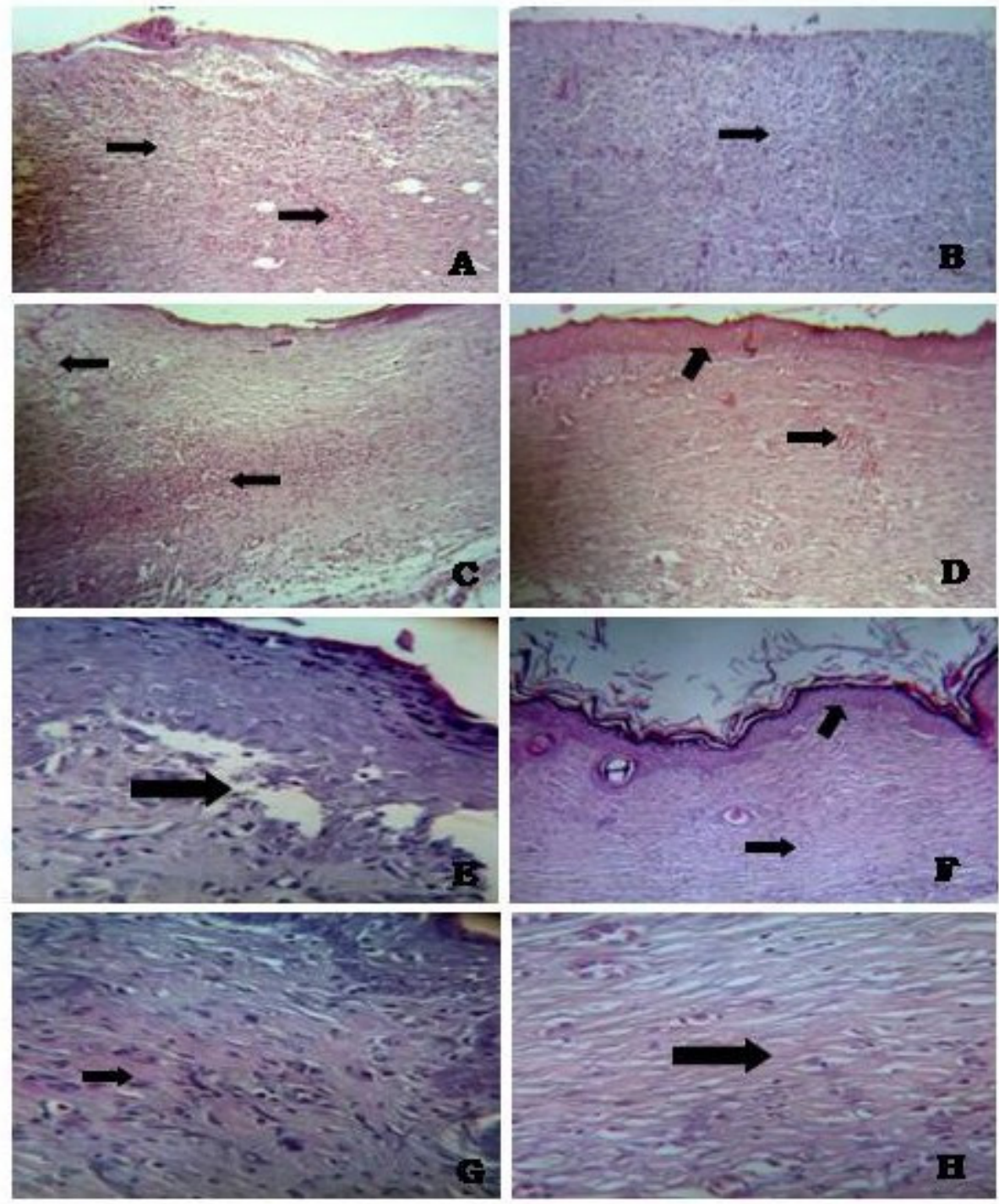

Figura 1. Fotomicrografias de feridas experimentais sépticas, de dorso de ratos Wistar, não tratadas (Grupo I) com 7 (A), 14 (C) e 21 ( $\mathrm{E}$ e $\mathrm{G}$ ) dias. A. Abundante exsudato inflamatório (seta) e tecido de granulação desorganizado composto por fibroblastos e vasos neoformados (seta), com 07 dias (10x). C. Presença de pequenos abscessos (seta), tecido de granulação exuberante e desorganizado; e infiltrado inflamatório mononuclear difuso (seta), com 14 dias (10x). E e G. Presença de abscesso (seta) abaixo da epiderme; e tecido de granulação exuberante (seta), com 21 dias (40x). E fotomicrografias de feridas experimentais contaminadas (Grupo II), de dorso de ratos Wistar, tratadas com soluções de papaína (10\%, 6\% e 4\%), com 7 (B), 14 (D) e 21 (F e G) dias. B. Presença de abundante exsudato inflamatório (seta) (10x); e tecido de granulação desorganizado, com 7 dias (10x). D. Presença de exuberante proliferação de células da epiderme (seta); e tecido de granulação organizado, com fibroblastos e vasos neoformados (seta), e redução do infiltrado inflamatório, com 14 dias (10x). F e H. Presença de epiderme totalmente reconstituída (seta) (10x), e tecido conjuntivo denso organizado (setas) (40x), com 21 dias.

Com 14 dias, observou-se que nos animais tratados com papaína a 6\% (Grupo II) as lesões caracterizaram-se por tecido de granulação exuberante, formado por tecido conjuntivo denso, com abundante quantidade de fibroblastos e matriz colágeno (organizada), e discreta neovascularização; além de infiltrado inflamatório mononuclear difuso e proliferação de células da camada germinativa da epiderme (Figura 1D). Porém, nos animais do Grupo I (contro- le não tratados), para o mesmo período, as lesões caracterizaram-se pela presença de tecido de granulação exuberante e desorganizado, composto por fibroblastos e matriz colágeno, e neovascularização moderada; infiltrado inflamatório mononuclear difuso formando pequenos abscessos; e proliferação de células da camada germinativa da epiderme (Figura 1C).

No $21^{\circ}$ dia observou-se que nas lesões dos animais tratados com papaína a 4\% (Grupo II), ocorreu a 
substituição total do tecido de granulação por tecido conjuntivo denso, com organização da matriz colágeno, e diminuição e amadurecimento dos vasos neoformados; além de epiderme totalmente reconstituída (Figuras $1 \mathrm{~F}$ e $1 \mathrm{H}$ ). Enquanto que no Grupo I (controle sem tratamento), para o mesmo período, observou-se a presença de: (1) abscesso purulento abaixo da epiderme, e (2) tecido de granulação exuberante, composto por matriz colágeno desorganizada, fibroblastos e presença de vasos neoformados maduros. Além de epiderme totalmente reconstituída (Figura 1E e 1G).

Os Resultados histométricos obtidos em microscopia de luz comum de ambos os grupos estão dispostos nas Tabelas 1 e 2 .
A papaína é uma substância muito utilizada no auxílio do tratamento de processos de cicatrização de lesões teciduais ulcerativas, associadas ou não a processos infecciosos, principalmente por acelerar o processo cicatricial tecidual ${ }^{3,6,7,9,10,12,13,14,21,23,24}$. Todavia, poucos são os estudos experimentais, na literatura, que demonstram de forma clara as ações da papaína sobre o tecido inflamado e de granulação, com ou sem a presença de agentes infecciosos, durante o processo de cicatrização tecidual ${ }^{7,21,25}$.

Neste estudo experimental tentou-se verificar a eficiência do tratamento com várias concentrações de soluções de papaína sobre feridas cirúrgicas contaminadas experimentalmente com Staphylococcus aureus. Para tanto se observou que o tratamento com

Tabela 1: Quantidade de leucócitos observados nas várias fases de cicatrização tecidual dos animais dos grupos controle (I) e tratados (II).

\begin{tabular}{|c|c|c|c|c|c|c|}
\hline & \multicolumn{2}{|c|}{$7^{\circ} \mathrm{dia}^{*}$} & \multicolumn{2}{|c|}{$14^{\circ} \mathrm{dia}^{*}$} & \multicolumn{2}{|c|}{$21^{\circ} \mathrm{dia}^{*}$} \\
\hline & I & II & I & II & I & II \\
\hline & 65 & 60 & 36 & 17 & 7 & 3 \\
\hline & 67 & 61 & 41 & 15 & 6 & 2 \\
\hline & 69 & 59 & 37 & 19 & 5 & 2 \\
\hline & 62 & 57 & 38 & 18 & 7 & 1 \\
\hline & 64 & 63 & 39 & 16 & 8 & 3 \\
\hline Média & 65,4 & 60 & 38,2 & 17 & 6,6 & 2,2 \\
\hline Desvio Padrão & 2,701 & 2,236 & 1,923 & 1,581 & 1,140 & 0,836 \\
\hline
\end{tabular}

${ }^{*} p<0.05$

Tabela 2. Quantidade de fibroblastos observados nas várias fases de cicatrização tecidual dos animais dos grupos controle (I) e tratados (II).

\begin{tabular}{|c|c|c|c|c|c|c|}
\hline & \multicolumn{2}{|c|}{$7^{\circ} \mathrm{dia}^{*}$} & \multicolumn{2}{|c|}{$14^{\circ} \mathrm{dia}^{*}$} & \multicolumn{2}{|c|}{$21^{\circ} \mathrm{dia}^{*}$} \\
\hline & $* * \mid$ & $* \star \|$ & ${ }^{* *} \mid$ & **II & I & II \\
\hline & 105 & 87 & 83 & 108 & 51 & 37 \\
\hline & 107 & 79 & 84 & 109 & 56 & 39 \\
\hline & 103 & 85 & 86 & 110 & 53 & 35 \\
\hline & 109 & 82 & 82 & 104 & 55 & 33 \\
\hline & 108 & 91 & 87 & 111 & 52 & 30 \\
\hline Média & 106,4 & 84,8 & 84,4 & 108,4 & 53,4 & 34,8 \\
\hline Desv. Padrão & 2,408 & 4,604 & 2,073 & 2,701 & 2,073 & 3,492 \\
\hline
\end{tabular}

${ }^{*} p<0.05 /{ }^{* *} p>0.05$ 
solução de papaína a 10\%, nestas condições, foi efetivo na fase inflamatória do processo de cicatrização tecidual séptica, contribuindo de forma importante para a diminuição do exsudato inflamatório, auxiliando na lise dos restos necróticos e manutenção do controle da infecção, em comparação com o grupo controle. Este fato é corroborado por outros autores na literatura com estudos clínicos em humanos para lesões sépticas ${ }^{2,3,6,8,9,10,11,12,14,15,16,17,18,19,25 . ~}$

A utilização de soluções de papaína a $10 \%$ e $6 \%$ mostrou-se efetiva para o desenvolvimento da fase de fibroplasia, com o auxílio na formação do tecido de granulação denso e remodelagem tecidual, abundante quantidade de fibroblastos e matriz colágeno, e discreta neovascularização; além de proliferação de células da camada germinativa da epiderme, sem a formação de abscessos, em comparação com o grupo controle. Dados semelhantes aos observados com estudos clínicos na literatura também mostraram que, nestas concentrações de uso da papaína, acontece uma aceleração na transformação da fase proliferativa para a fase maturativa do processo de cicatrização com organização espacial das fibras colágeno e consequente diminuição da neovascularização e remodelação do tecido ${ }^{6,8,9,10,11,12,14,19,20,21,24}$.

O uso de soluções de papaína a $4 \%$, do $15^{\circ}$ até o $21^{\circ}$ dia de tratamento, nos animais deste grupo (Grupo II) sugeriu que o processo de cicatrização tecidual foi mais efetivo que o observado no Grupo I (controle) com a cessação do processo inflamatório, total substituição do tecido de granulação por tecido conjuntivo denso, diminuição e amadurecimento dos vasos neoformados; além de reconstituição total das camadas da epiderme. Diferentemente do observado no grupo controle.

O presente estudo sugere, então, e em acordo com a literatura $23,6,67,8,9,10,11,12,14,15,16,19,20,21,23,24$, que antes de se iniciar qualquer tratamento de lesões contaminadas, com soluções de papaína, deve-se levar em consideração a fase em que se encontra a lesão, o tipo e as características individuais de cada uma destas.

Estes dados são semelhantes ainda aos resultados microscópicos obtidos por Sanchez et al. ${ }^{7}$ em seus estudos com animais tratados com papaína a $2 \%$, exceto pelo fato de que estes autores observaram que, com 07 dias de análise houve a manutenção da crosta hemato-fibrinosa e, com 21 dias o tecido de granulação era rico em fibras colágenas menos organizado; o que difere dos dados observados no presente estudo possivelmente em função na variação da concentração de papaína adotada.

Na bibliografia Norte-Americana, entretanto, o uso da papaína isoladamente é considerado pouco efetivo. De tal modo que se admite que a papaína tenha suas ações debridantes e cicatrizantes mais efetivas, quando em associação com um agente ativador (Uréia) ${ }^{17}$. No entanto, isto não tem sido evidenciado em experiências clínicas no Brasile,3,6,8,9,10,11,12,18,19.

Ressalta-se, ainda, a importância da contribuição científica deste estudo experimental para o entendimento da ação da papaína nos processos de cicatrização de lesões contaminadas, visto a carência de artigos científicos atuais tratando deste assunto na literatura. Ainda assim, porém, mais estudos clínicos controlados em humanos devem ser conduzidos para determinar o papel terapêutico da papaí$\mathrm{na}^{4,5,6,7,8,10,11,12,14,17,23,25}$ frente aos demais métodos de cicatrização de lesões contaminadas hoje disponíveis.

\section{Conclusão}

Nosso estudo sugere que a utilização da papaína em concentrações diferentes, conforme a fase em que se encontra uma lesão tecidual contaminada, pode auxiliar de forma positiva para o debridamento da lesão, redução do tempo de permanência da crosta hemato-fibrinosa e redução do tempo de neoformação da epiderme com reorganização da derme durante o processo de cicatrização tecidual.

\section{Agradecimentos}

Agradecemos cordialmente ao Dr Paulo Sergio Roffe Azevedo, todos do Laboratório de Patologia Clínica Dr. Paulo C. Azevedo pelo apoio logístico e técnico dado para o desenvolvimento deste trabalho.

\section{Referencias}

1. Otuka ES, Pedrazzani ES, Pioto MP. Uso da papaína na úlcera plantar. Rev Bras Enferm. 1996;49:207-14.

2. Udod VM, Storojuk VT. Use of papain in treating suppurative postoperative soft tissue complications and deseases. Khirurgiia (Mosk). 1981;5:99-101.

3. Rogenski NMB, Guedes ML, Baptista CMC, Costa LDF. Uso de papaína em infecções de vísceras. Rev Bras Enferm. 1995;48:140-3.

4. Nagapetian KhO, Bagdasarian RV, Matinian LA, Mirzoyan VS. Treatment of supperative wounds with lekopain in a polyclinic. Khirurgiia (Mosk). 1986;6:17-21. 
5. Masini E, Calamo MA. Uma forma de tratamento de lesões cutâneas com papaína e sacarose. Rev Bras ClinTer. 1986; 15:245-8.

6. Monetta L. Análise evolutiva do processo de cicatrização em úlceras diabéticas, de pressão e venosa com uso da papaína. [Dissertação]. São Paulo: EEUSP; 1998.

7. Sanchez Neto R, Barone B, Teves DC, Simões MJ, Novo NF, Juliano Y. Aspectos morfológicos e morfométricos da reparação tecidual de feridas cutâneas de ratos com e sem tratamento com solução de papaína a $2 \%$. Acta Cir Bras. 1993;8:18-23.

8. Wiseman A. Topics in enzyme and fermentation biotechnology. Chischester: Ellis Horwood; 1980. 4119-26p.

9. Monetta L. Utilização de novos recursos em curativos num consultório de enfermagem. Rev Paul Enferm. 1992;11:1926.

10. Jorge AS, Dantas SRPE. Abordagem multiprofissional do tratamento de feridas. São Paulo: Atheneu; 2003. 123-131p.

11. Monetta L. A importância da atuação científica do enfermeiro na execução dos curativos feitos com papaína. Rev Bras Enferm. 1990;9:83-7.

12. Rogenski NMB, Baptista CMC, Sofia MH. O uso da papaína a $2 \%$ nas lesões provocadas pela síndrome de Fournier: a propósito de 14 casos. Rev Paul Enferm. 1998;17:39-45.

13. Mandelbaum SH, Di Santis EP, Mandelbaum MHS. Cicatrização: conceitos atuais e recursos auxiliares - Parte I. An Bras Dermatol. 2003;78:393-408.

14. Mandelbaum SH, Di Santis EP, Mandelbaum MHS. Cicatrization: current concepts and auxiliary resources - Part II. An Bras Dermatol. 2003;78:521-2.

15. Gonçalves G, Parizotto NA. Fisiopatologia da reparação cutânea: atuação da fisioterapia. Rev Bras Fisioter. 1998;3:5-13.
16. Carrico TJ, Mehrhof Junior Al, Cohen IK. Biologia da cicatrização dos feridos. Clin Cir Am Norte. 1984;4:763-77.

17. Balbino CA, Pereira LME, Curi R. Mecanismos envolvidos na cicatrização: uma revisão. Rev Bras Cienc Farm. 2005;412751.

18. Alvarez OM, Fernandez-Obregon AC, Rogers RS, Bergamo L, Masso J, Black M. Chemical debridement of pressure ulcers: a prospective, randomized, comparative trial of collagenase and papain/urea formulations. Wounds. 2001;12:1525.

19. Monetta L. Uso da papaína nos curativos feitos pela enfermagem. Rev Bras Enferm. 1987;40:66-73.

20. Clark RAF. Biology of dermal wound repair dermatological clinics. J Invest Dermatol. 1993;11:647- 61.

21. Rocha RPA, Gurjão WS, Brito Junior LC. Cicatrização de úlceras teciduais não infectadas tratadas com papaína. Rev. Para. Med. 23(4), 2009.

22. Lima MB, Matins Filho ES, Carvalho RG, Brito Junior LC. Estudo in vitro da ação bactericida e/ou bacteriostática da papaína. Rev. Para. Med;23(2). 2009.

23. Carvalho FIC, Silva JPN, Bittencourt MC, Brito Junior LC. Uso de apaína no tratamento de lesões ulcerativas de pacientes portadores de pé diabético: relato de cinco casos. Rev. Para. Med; 24(2), 2010.

24. Martins MD, Fernandes KPS, Pavesi VC, França CM, MesquitaFerrari RA, Bussadori SK. Healing properties of papain-based gel on oral ulcers. Braz J Oral Sci. 2011; 10:120-3.

25. Payne WG, Salas RE, Ko F, Naidu DK, Donate G, Wright TE, Robson MC. Enzymatic debriding agents are safe in wounds with high bacterial bioburdens and stimulate healing. Eplasty. 2008; 7:151-7. 